\section{0b MAINSTREAMING GENDER INTO OCCUPATIONAL SAFETY AND HEALTH (OSH) PRACTICE}

SM Copsey*, Elke Schneider. European Agency for Safety and Health at Work (EU-OSHA)

\subsection{6/oemed-2018-ICOHabstracts.1509}

Introduction Women and men are different, and the jobs they do, their working conditions and circumstances and how society treats them are different, affecting the occupational risks they face: a gender-sensitive prevention approach is required. However, gender mainstreaming and taking a gender-sensitive approach are not always well understood in OSH. Practice needs to be exchanged and experiences shared in order to debunk some of the myths and barriers. This project researched examples of policies, programmes and practices from across the EU and worldwide to illustrate gender approaches in OSH.

Methods The cases cover approaches by national and intermediary organisations and gender-sensitive approaches to $\mathrm{OSH}$ in the workplace. Detailed descriptions of a range of cases were made, covering the development process and what was achieved. Brief summaries of additional examples were made. The cases were analysed for success factors, challenges, drivers and transferability.

Results The cases were varied, covering: integrating gender mainstreaming into organisations' planning, administration and daily working practices; developing methods and tools to promote gender mainstreaming; facilitating working conditions suitable for both women and men, including both health and human resources management; the reconciliation of work and family life and thereby promoting better work-life balance; ensuring women are encouraged and supported in working in male-dominated professions; designing and promoting personal protective equipment (PPE) for women; conducting awarenessraising campaigns on health.

Discussion Men and women benefit when gender differences are recognised and are addressed in OSH. The report shows that this is happening in many different ways, through policy and strategy, research and at the workplace. Those taking action include scientific associations, OSH organisations, equalities organisations, health organisations, employers and trade unions. The cases range from comprehensive gender-mainstreaming projects to simple steps that organisations can take to ensure that the $\mathrm{OSH}$ of both male and female workers is covered.

\section{C BALANCE OF INFORMAL WORKERS IN LATIN AMERICA: CHALLENGES AND BARRIERS TO ACCESS TO HEALTH AND SOCIAL SECURITY}

O Solar*, P Bernales, MJ Gonzalez, A Riesco, A Vives. Work, Employment and Health Inequities, Faculty of Social Science of Latin America (FLACSO), Santiago, Chile

\subsection{6/oemed-2018-ICOHabstracts. 1510}

Introduction Employment and working conditions are recognised as social determinants of health; however, there are limited data on the relationship of informal work and employment conditions with health inequalities.

Methods As part of The Work, Employment, and Health Equity Program was conducted a study to identify available data on informal work and access to health and social security in 12 countries in Latin America. We then measured the magnitude of informality, contextual factors related to informal work, and the characteristics of informal workers and their health. The methodology included Case Studies were oriented to analyse access to health and social security, their employment and working conditions and their relationship to the characteristics of the countries' economic structure; Focus group Studies collected the primary information based on the informal workers' perception and measured the magnitude of informality, contextual factors related to informal work, and the characteristics of informal workers and their health

Result In Latin America, informal work is higher among women than among men. Analyses showed that health status, access to services and financial protection was poorer among informal compared to formal workers. People work informal economy are higher rate of work among eldest and youngest groups and living in urban and rural.

Discussion Despite limited secondary data on informal work and health in some countries, our results suggest that informal workers are a large and diverse proportion of the working population in Latin America. Employment and working conditions must be studied further to understand the unique risks and drivers of health inequalities in addition to informing effective policies and programs to promote the health of workers worldwide. The lack of evidence on this subject has been detrimental to the development of sound policies addressing access to health by people-WIE and their families.

\section{WORKING WOMEN AND MIGRATION: NEVER-ENDING CHALLENGES?}

${ }^{1}$ Rima Habib*, ${ }^{2}$ Julietta Rodriguez-Guzman*. 'Professor and Chair, Dept. of Environmental Health, Fac. of Health Sciences, American University of Beirut, Beirut, Lebanon; ${ }^{2}$ Professor Associate, Graduate Program on Occupational Health, Fac. of Medicine, El Bosque University, Bogota, Colombia

\subsection{6/oemed-2018-ICOHabstracts. 1511}

The aim of this special session To address the challenging working, employment and living conditions that migrant women workers face in unequal foreign the labour markets.

${ }^{1} \mathrm{~J}$ Fanchette, ${ }^{2} \mathrm{I}$ Bello, ${ }^{3} \mathrm{~N}$ Lepink

${ }^{1}$ Scientific Action Group, PREVOR, Valmondois, France

${ }^{2}$ Dr. University of Carabobo, Valencia, Venezuela

${ }^{3}$ Dr. International Labour Office, Geneva, Swiss

\section{9a MIGRANT WORKERS OF THE HEALTH SECTOR}

J Bigaignon-Fanchette*, Laurence Mathieu, Joel Blomet. Scientific Action Group, Head management, PREVOR, Valmondois, France

\subsection{6/oemed-2018-ICOHabstracts.1512}

Introduction The severe shortage of health workers in developed and developing countries is a critical issue that must be addressed as an integral part of strengthening health systems. Migration of health-care workers has a long history. Each country facing shortages of health workers needs to identify the underlying reasons for the shortages, determine what motivates health workers to remain in the health sector, and evaluate the incentives required for maintaining a competent and motivated health workforce

Objectives Highlight the situation of health workers in developed countries as well as developing countries, to gain a better understanding of the contributing factors to health worker motivation, dissatisfaction and migration. 